\title{
Empirical Evidence of the Negative Relationship between Social Capital and Corruption
}

\author{
Kanybek Nur-tegin* \\ Associate Professor of Economics \\ Wilkes Honors College, Florida Atlantic University \\ 5353 Parkside Drive, Jupiter, FL 33458
}

\begin{abstract}
It is theorized that societies with higher social capital, as indicated by stronger civic associations and more trust among citizens, tend to have lower levels of government corruption. This hypothesis has been difficult to evaluate empirically because of a lack of reliable data to measure both social capital and corruption. Furthermore, with unreliable data it has been difficult to isolate the causal direction between social capital and corruption as it is possible that a positive association between the two variables could be driven by an omitted variable or the flow of causation could run from corruption to social capital. In this paper, we use new micro-level international data on social capital and corruption, and a unique historical instrumental variable to provide empirical evidence that higher social capital leads to lower levels of corruption. Our results are causal and robust to alternative specifications of the regression models.
\end{abstract}

Keywords: social capital, trust, civic associations, corruption, bribery.

JEL codes: $017, \mathrm{D} 73, \mathrm{Z13}$

* Corresponding author 
